\title{
Produção de chicória em função de doses de nitrogênio e potássio aplicadas na fase de mudas
}

\author{
Antonio Ismael Inácio Cardoso; Antonio José Ustulin Filho \\ UNESP-FCA, Depto. Departamento de Horticultura, C. Postal 237, 18603-970 Botucatu-SP; ismaeldh@fca.unesp.br; ajufilho@yahoo. \\ com.br
}

\section{RESUMO}

Considerando a escassez de estudos relacionando à adubação em mudas de olerícolas com a produção final, realizou-se o presente trabalho com o objetivo de estudar o efeito de doses de nitrogênio e potássio, aplicados via fertirrigação, na produção de mudas de chicória, cultivadas em substrato à base de fibra de coco e sua influência na produção final. Foram realizados dois experimentos, o primeiro com quatro tratamentos variando doses de nitrogênio e o segundo com quatro tratamentos variando doses de potássio. Em ambos, o delineamento experimental utilizado foi em blocos casualizados, com quatro repetições. Para o primeiro experimento, utilizou-se, semanalmente, o nitrato de amônio nas doses de 0; 40;80 e 120 $\mathrm{mg}$ de $\mathrm{N} \mathrm{L}^{-1}$, enquanto que para o segundo experimento, usou-se, semanalmente, o cloreto de potássio nas doses de $0 ; 70 ; 140$ e 210 $\mathrm{mg}$ de $\mathrm{K}_{2} \mathrm{O} \mathrm{L}^{-1}$. As características avaliadas nas mudas foram altura da parte aérea, número de folhas, massa da matéria fresca e seca da parte aérea. Na planta, após a colheita, avaliou-se altura e diâmetro da "cabeça", número de folhas e massa da matéria fresca. As doses de potássio não influenciaram as características de mudas, nem as plantas ao final do ciclo. Para todas as características avaliadas nas mudas, houve aumento linear em função do incremento das doses de N. No entanto, para a massa da matéria fresca, diâmetro e número de folhas por "cabeça" o efeito foi quadrático. Recomenda-se a dose de $90 \mathrm{mg}_{\text {de }} \mathrm{N} \mathrm{L}^{-1}$, por proporcionar maior massa da matéria fresca e número de folhas na colheita.

Palavras chave: Cichorium endivia, adubação, fibra de coco, fertirrigação.

\begin{abstract}
Endive yield depending on nitrogen and potassium rates applied on the seedlings

Considering there are few researches about the influence of seedlings fertilization on yield, this work was carried out in order to evaluate the effect of rates of nitrogen and potassium, applied by fertirrigation, in endive seedlings on yield. Two experiments were carried out, the first with four treatments, varying nitrogen rates, and the second with four potassium rates. In both, experimental design was randomized blocks, with four replications. In the first experiment, we utilized ammonium nitrate, weekly, at rates 0; 40; 80 and $120 \mathrm{mg}$ of $\mathrm{N} \mathrm{L}^{-1}$, while in the second experiment we utilized potassium chloride, weekly, at rates $0 ; 70 ; 140$ and $210 \mathrm{mg}$ of $\mathrm{K}_{2} \mathrm{O}$ $\mathrm{L}^{-1}$. The evaluated characteristics at seedling stage were shoot height, number of leaves, fresh and dry shoot weight. At harvesting, we evaluated plant height, diameter, number of leaves and fresh weight. Potassium rates did not influence all characteristics, at seedling and at harvesting stages. For all seedling characteristics, there was linear increasing depending on nitrogen rates. But, for plant fresh weight, diameter and number of leaves at harvesting, the effect was quadratic. The highest fresh weight and number of leaves at harvesting were obtained with $90 \mathrm{mg}$ of $\mathrm{N} \mathrm{L}^{-1}$.
\end{abstract}

Keywords: Cichorium endivia, fertilization, coconut fiber, fertirrigation.

\section{(Recebido para publicação em 21 de dezembro de 2012; aceito em 30 de outubro de 2013) (Received on December 21, 2012; accepted on October 30, 2013)}

\begin{abstract}
$\mathrm{A}$ s asteráceas abrangem as hortaliças herbáceas mais consumidas na forma de saladas, com grande aceitação popular. A planta da chicória (Cichorium endivia) é muito semelhante à da alface, principal representante da família. É uma espécie que produz melhor sob temperaturas amenas, embora existam cultivares tolerantes a temperaturas mais elevadas. Há dois tipos de cultivares: chicória lisa (escarola) e crespa (endívia).
\end{abstract}

A propagação se efetua pela semeadura em bandeja para produção de mudas, seguida por transplante (Filgueira,
2008). Segundo Minami (2010), para a produção de mudas de hortaliças, o substrato deve proporcionar condições favoráveis para o desenvolvimento do sistema radicular da plântula, fornecendo à planta sustentação, nutrientes, água e oxigênio, exercendo a função do solo. Porém, os teores de nutrientes nos substratos nem sempre são suficientes para promover o desenvolvimento satisfatório das mudas. Existem substratos de diferentes marcas, com diferentes origens e diferentes características químicas e físicas para produção de mudas de hortaliças, fazendo com que o manejo da adubação seja bastante complexo.

A fibra da casca do coco verde é matéria prima importante na produção de substratos de boa qualidade para a produção de mudas ou em cultivos sem o uso do solo. A facilidade de produção, baixo custo e alta disponibilidade são algumas vantagens apresentadas por este tipo de substrato, além de ser um produto renovável (Carrijo et al., 2002). No entanto, o substrato feito a partir das fibras de coco é pobre em nutrientes para as plantas. Silveira et al. (2002) relataram baixo desenvolvimento das mudas de tomateiro com este substrato devido, 
principalmente, ao reduzido teor de nutrientes. Portanto, é preciso fornecê-los de acordo com as necessidades da espécie a ser cultivada, adicionando-se adubos em pré-plantio ou, principalmente, em fertirrigação.

Müller et al. (2010), estudando o efeito da urina-de-vaca, rica em potássio e nitrogênio, na produção de mudas de chicória, concluíram que a mesma não atingiu o mesmo padrão que mudas adubadas com fertilizante mineral e que doses elevadas da mesma mostram-se fitotóxicas. Não há relatos de utilização de fibra de coco na produção de mudas de chicória. Existem estudos em abóbora (Higuti et al., 2010), berinjela (Oliveira et al., 2009), melancia (Ramos et al., 2012), pimentão (Braga et al., 2007) e tomate (Silveira et al., 2002; Costa et al., 2007; Sampaio et al., 2008). No entanto, na maioria das vezes, avalia-se apenas a muda, sem estudar o efeito do transplante até a colheita. A presente pesquisa objetivou avaliar o efeito de doses de nitrogênio e potássio, aplicados via fertirrigação, na produção de mudas de chicória e sua influência na produção final.

\section{MATERIAL E MÉTODOS}

Os experimentos foram realizados em campo da UNESP em Botucatu. O clima da região de São Manuel-SP, conforme os critérios adotados por Köppen, baseado nas observações meteorológicas, é Cfa [Clima temperado quente (mesotérmico) úmido]. A temperatura média do mês mais quente é superior a $22^{\circ} \mathrm{C}$ e a do mês mais frio é de $17,5^{\circ} \mathrm{C}$, com temperatura média anual de $21^{\circ} \mathrm{C}$ e total médio de precipitação anual de $1445 \mathrm{~mm}$ (média de 27 anos) (Cunha \& Martins, 2009).

Foram realizados dois experimentos, o primeiro com quatro tratamentos, testando doses de nitrogênio $(\mathrm{N})$, e o segundo com quatro doses de potássio $\left(\mathrm{K}_{2} \mathrm{O}\right)$. Em ambos, o delineamento experimental utilizado foi em blocos casualizados, com quatro repetições. A semeadura da chicória lisa, cultivar Malan, foi realizada em bandejas de polietileno com 200 células no dia 25 de outubro de 2011, utilizando-se como substrato a fibra de coco de uma marca comercial. Em cada bandeja foram utilizadas cinco linhas com dez células para cada parcela, totalizando os quatro tratamentos de cada bloco por bandeja. Das cinco linhas, a primeira e a última foram usadas como bordadura, bem como a primeira e última coluna de cada bandeja. As bandejas foram mantidas em casa de vegetação do tipo arco, com pé direito de $2,8 \mathrm{~m}$, largura de $7 \mathrm{~m}$, comprimento de $20 \mathrm{~m}$ e cobertura de polietileno transparente de $150 \mu \mathrm{m}$ de espessura, com tela anti afídeos nas laterais.

Para o primeiro experimento, variando doses de nitrogênio, utilizou-se o nitrato de amônio $(32 \%$ de $\mathrm{N})$ nas doses de $0 ; 40 ; 80$ e $120 \mathrm{mg}$ de $\mathrm{N} \mathrm{L}^{-1}$, enquanto que para o segundo experimento, aplicou-se o cloreto de potássio $(60 \%$ de $\mathrm{K}_{2} \mathrm{O}$ ) nas doses de $0 ; 70 ; 140$ e $210 \mathrm{mg}$ de $\mathrm{K}_{2} \mathrm{O} \mathrm{L}^{-1}$. Optou-se por estudar estas doses após estudos prévios realizados com alface, espécie da mesma família da chicória, e após consultar alguns viveiristas no estado de São Paulo. Adubou-se, também, com magnésio, fósforo e cálcio nas doses 50,100 e $60 \mathrm{mg} \mathrm{L}^{-1}$, respectivamente, em cada fertirrigação, para ambos experimentos, usando-se como fonte sulfato de magnésio $(9 \% \mathrm{Mg}$ e $14 \% \mathrm{~S})$, superfosfato triplo $\left(41 \% \mathrm{P}_{2} \mathrm{O}_{5}\right.$ e $\left.14 \% \mathrm{Ca}\right)$ e cloreto de cálcio $(24 \% \mathrm{Ca})$, respectivamente. Quando variou-se o nitrogênio, a dose de potássio aplicada na fertirrigação foi de $140 \mathrm{mg}$ de $\mathrm{K}_{2} \mathrm{O} \mathrm{L}^{-1}$, enquanto que no experimento variando as doses de potássio, a dose de nitrogênio aplicada foi de $80 \mathrm{mg}$ de $\mathrm{N} \mathrm{L}^{-1}$.

As fertirrigações foram realizadas uma vez por semana, utilizando-se um regador com crivo fino, iniciando-se no dia 31 de outubro de 2011, quando as mudas começaram a se desenvolver, e encerrando-se no dia 02 de dezembro de 2011, próximo da data do transplante. Foram utilizados, em cada aplicação, $100 \mathrm{~mL}$ da solução de nitrogênio, ou potássio, em cada parcela com 50 células (plântulas). Em seguida, aplicava-se $100 \mathrm{~mL}$ por parcela da solução contendo os outros nutrientes. Foram, portanto, 2 $\mathrm{mL}$ de cada solução em cada célula por aplicação.

As mudas foram transplantadas no dia 07 de dezembro de 2011 em canteiros com 1,0 m de largura e 0,2 $\mathrm{m}$ de altura em campo aberto. As parcelas foram compostas por três fileiras longitudinais de plantas arranjadas no espaçamento de $30 \times 30 \mathrm{~cm}$, totalizando 12 plantas por parcela. O delineamento experimental foi em blocos casualizados, com as mesmas quatro repetições originais das bandejas.

O solo é um Latossolo Vermelho Distrófico Típico. É um solo arenoso, com 836,116 e $48 \mathrm{~g} \mathrm{~kg}^{-1}$ de areia, de silte e de argila, respectivamente. Os resultados obtidos na análise química, segundo metodologia de Raij et al. (2001), na camada de $0-20 \mathrm{~cm}$ de profundidade, antes da instalação do experimento foram: $\mathrm{pH}_{(\mathrm{CaCl} 2)}=6,3$; matéria orgânica $=10 \mathrm{~g} \mathrm{dm}^{-3} ; \mathrm{P}_{\text {resina }}=22 \mathrm{mg} \mathrm{dm}^{-3} ; \mathrm{H}+\mathrm{Al}=$ $13 \mathrm{mmol}_{\mathrm{c}} \mathrm{dm}^{-3} ; \mathrm{K}=1,4 \mathrm{mmol}_{\mathrm{c}} \mathrm{dm}^{-3}$; $\mathrm{Ca}=36 \mathrm{mmol}_{\mathrm{c}} \mathrm{dm}^{-3} ; \mathrm{Mg}=15 \mathrm{mmol}_{\mathrm{c}}$ $\mathrm{dm}^{-3} ; \mathrm{CTC}=65 \mathrm{mmol}_{\mathrm{c}} \mathrm{dm}^{-3} \mathrm{eV}=80 \%$. A adubação foi baseada na recomendação de Trani et al. (1997) para o estado de São Paulo, aplicando-se 40, 400 e 150 $\mathrm{kg} \mathrm{ha}^{-1}$ de N, $\mathrm{P}_{2} \mathrm{O}_{5}$ e $\mathrm{K}_{2} \mathrm{O}$ na forma de sulfato de amônia $(21 \% \mathrm{~N})$, superfosfato triplo $\left(41 \% \mathrm{P}_{2} \mathrm{O}_{5}\right.$ e $\left.14 \% \mathrm{Ca}\right)$ e cloreto de potássio $\left(60 \% \mathrm{~K}_{2} \mathrm{O}\right)$, respectivamente, além de $60 \mathrm{t} \mathrm{ha}^{-1}$ de composto orgânico da marca comercial Provaso ${ }^{\circledR}$.

A irrigação foi feita por microaspersão, aplicando-se cerca de $30 \mathrm{~mm}$ de água a cada dois dias. Foram realizadas adubações em cobertura aos 7; 14; 28 e 35 dias após o transplante, com 0,5 gramas de uréia $(45 \% \mathrm{~N})$ por planta, correspondendo à dose máxima para $\mathrm{a}$ cultura, $90 \mathrm{~kg} \mathrm{ha}^{-1}$ de $\mathrm{N}$, recomendada por Trani et al. (1997).

No dia do transplante, dez mudas por parcela foram separadas para avaliar a massa da matéria fresca da parte aérea, obtida pela pesagem em balança analítica; a altura da parte aérea, desde a superfície do substrato até a ponta da folha mais comprida, com auxílio de régua graduada; o número de folhas; e a massa da matéria seca da parte aérea, obtida após secagem por sete dias em estufa de ventilação forçada a $65^{\circ} \mathrm{C}$, e valores obtidos após pesagem em balança analítica.

A colheita foi realizada no dia $23 \mathrm{de}$ janeiro de 2012, para todos os tratamentos. Avaliou-se, em uma amostra de seis 
plantas por parcela, a altura da planta, distância da base da planta no solo à ponta da maior folha; o diâmetro da planta, com auxílio de régua graduada; número de folhas; e a massa da matéria fresca, com auxílio de balança analítica.

Foi realizada análise de variância e, no caso de F significativo a 5\% para os tratamentos (doses), foi realizada análise de regressão polinomial, utilizando-se o programa Estat.

\section{RESULTADOS E DISCUSSÃO}

Para todas as características avaliadas nas mudas, quanto maior a dose de nitrogênio, maior o valor, com aumento linear (Figura 1). Para exemplificar este resultado, para cada aumento na concentração da solução nutritiva em $10 \mathrm{mg} \mathrm{L}^{-1}$ de $\mathrm{N}$, obteve-se aumento de $48 \mathrm{mg}$ na massa da matéria fresca de cada muda. Resultado semelhante foi relatado por Higuti et al. (2010) na produção de mudas de abobrinha, também com substrato à base de fibra de coco, com maiores valores de massa da matéria fresca e seca quanto maior a dose de nitrogênio na fertirrigação das mudas. Tremblay \& Senécal (1988), Soundy (1996) e Vital et al. (2002) também obtiveram aumentos nos valores das características vegetativas das mudas de alface com o incremento da dose de nitrogênio.

Segundo Soundy (1996), doses elevadas de nitrogênio podem deixar a muda frágil e estiolada, com dificuldade de recuperação após o transplante. No entanto, observou-se que as mudas de todos os tratamentos se desenvolveram bem após o transplante. Esta tendência de estiolamento não foi vista, pois observa-se (Figura 1) que os valores de altura (3,9 a 5,5 cm) e massa fresca (235 a $812 \mathrm{mg}$ ) da parte aérea das mudas foram inferiores aos relatados por Reghin et al. (2007), também com bandejas com 200 células, que obtiveram 7,7 a 12,5 cm de altura e 1240 a $1800 \mathrm{mg}$ por muda para massa fresca.

Para as doses de nitrogênio, não foram obtidas diferenças para a altura da planta na colheita (média de 18,4 cm),

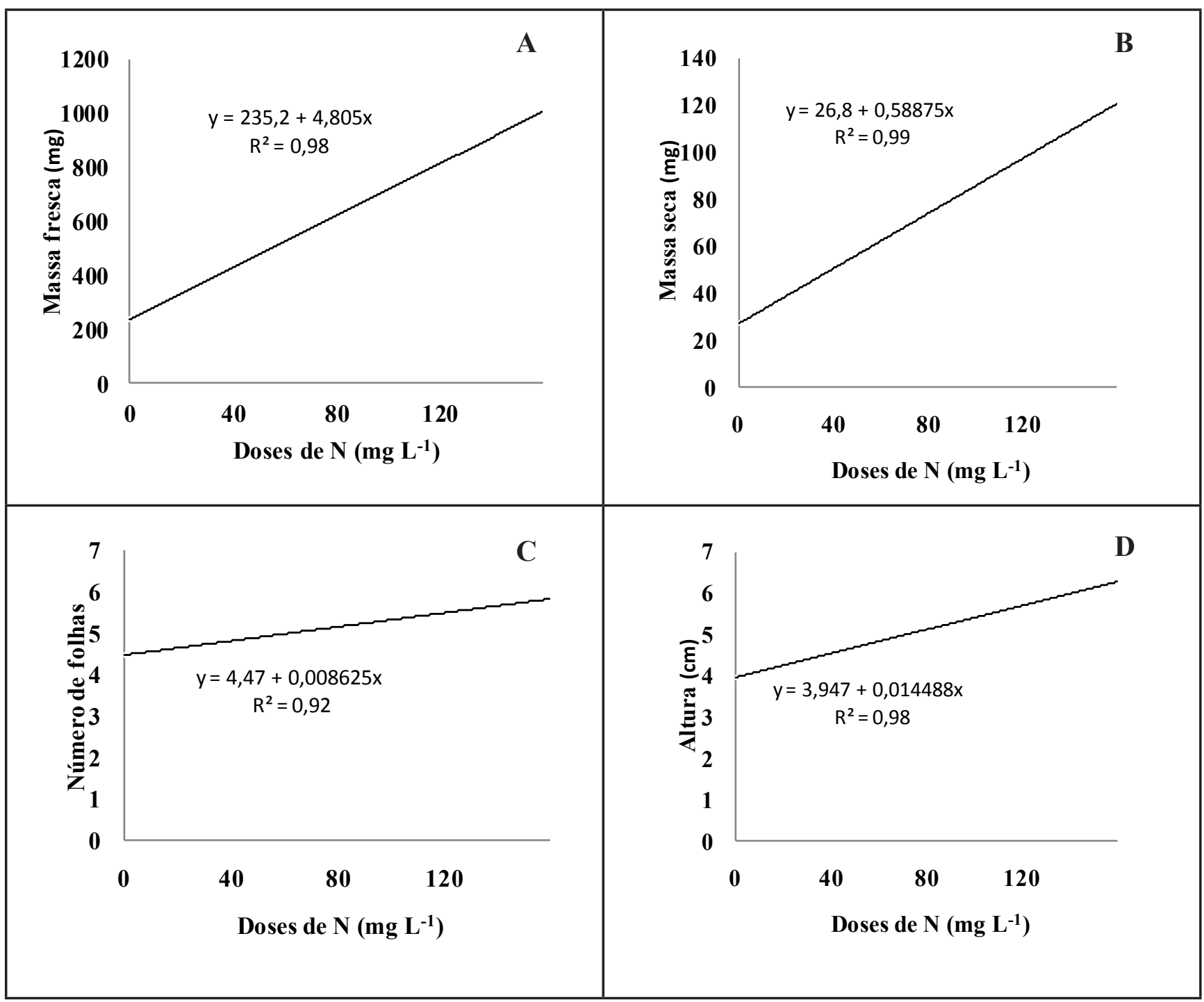

Figura 1. Massa da matéria fresca (A) e seca (B), número de folhas (C) e altura da parte aérea (D) de mudas de chicória aos 43 dias após a semeadura em função das doses de nitrogênio aplicadas em fertirrigação (fresh (A) and dry (B) weight, number of leaves (C) and seedling height (D) of endive 43 days after sowing depending on nitrogen rates applied in fertirrigation). São Manuel, UNESP, 2012. 


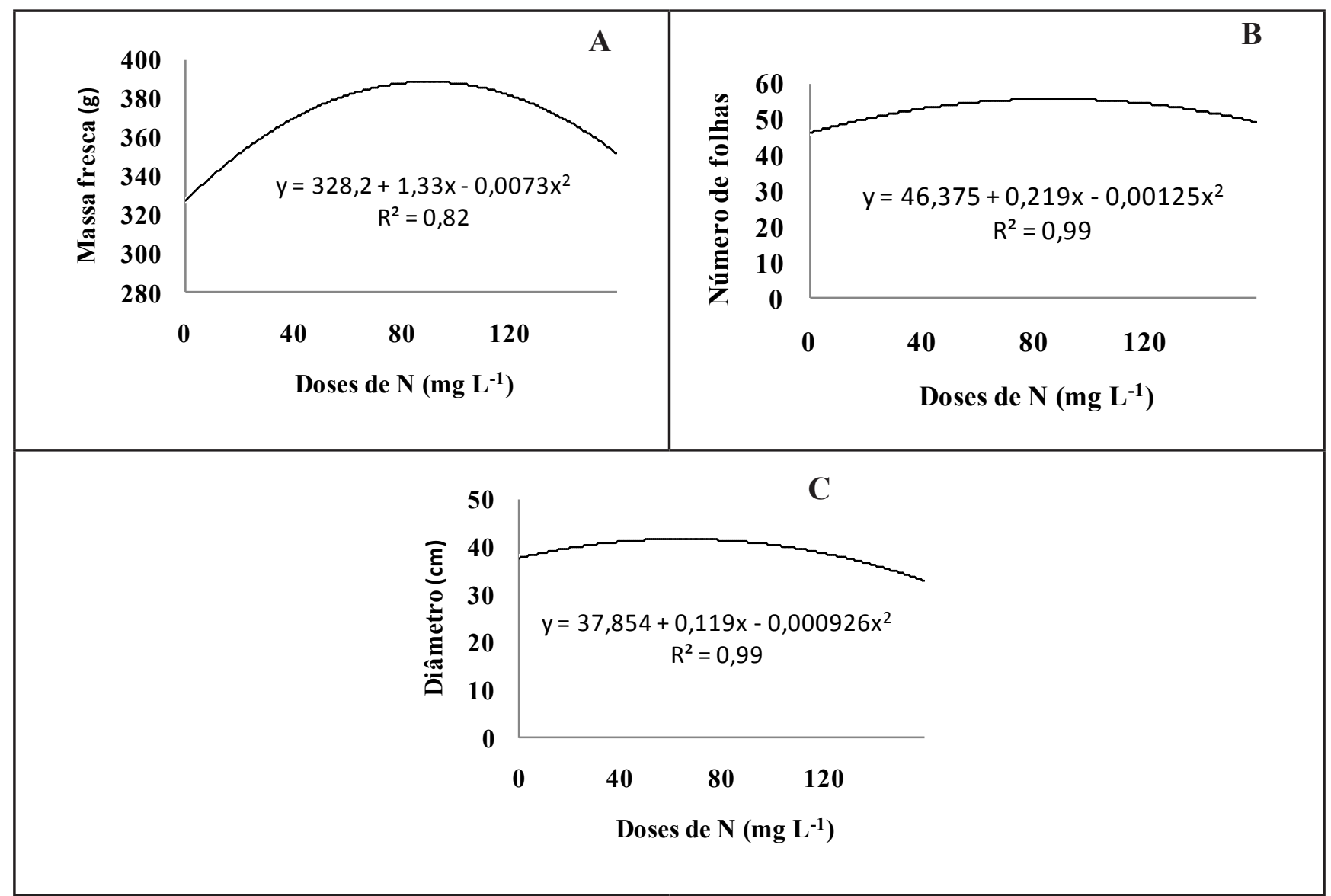

Figura 2. Massa da matéria fresca (A), diâmetro (B) e número de folhas (C) por planta de chicória na colheita aos 47 dias após o transplante em função das doses de nitrogênio aplicadas em fertirrigação na produção de mudas (fresh weight (A), diameter (B) and number of leaves (C) per plant of endive at harvesting 47 days after transplanting depending on nitrogen rates applied in fertirrigation at seedling production). São Manuel, UNESP, 2012.

porém, para a massa da matéria fresca, diâmetro e número de folhas por planta foram mensurados efeitos quadráticos (Figura 2). Para o diâmetro, o valor máximo estimado foi de $41,7 \mathrm{~cm}$ para a

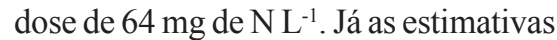
de máxima massa da matéria fresca (389 g) e número de folhas por planta (56 folhas) foram para doses semelhantes, 91 e $88 \mathrm{mg}$ de $\mathrm{N} \mathrm{L}^{-1}$, respectivamente. Portanto, apesar de quanto maior a dose de N, maiores os valores das características avaliadas na fase de mudas, este ajuste a funções lineares crescentes nestas características não se repetiu no final do ciclo da cultura. Mudas obtidas com a maior dose $(120 \mathrm{mg}$ de $\mathrm{N}$ $\left.\mathrm{L}^{-1}\right)$ resultaram em plantas com massa estimada de $382 \mathrm{~g}$, pouco inferior ao máximo. Ressalta-se que todas as plantas, independentemente do tratamento, receberam os mesmos tratos culturais após o transplante, incluindo adubação química e orgânica de plantio e em co- bertura. As condições favoráveis após o transplante, principalmente a adubação, favoreceram o desenvolvimento normal das plantas pois, mesmo na testemunha sem adubação nitrogenada nas mudas (plantas colhidas com $328 \mathrm{~g}$ ), a perda de produção foi pequena, $16 \%$ inferior em relação ao valor máximo. Reghin et al. (2007), ao utilizarem bandejas com 200 células, obtiveram plantas com massa de 332 a $407 \mathrm{~g}$, muito semelhante ao desta pesquisa. Os valores também são semelhantes aos obtidos por Feltrim et al. (2006) e Sá \& Reghin (2008) na ausência de cobertura das plantas com filmes protetores.

As doses de potássio não influenciaram as características avaliadas na fase de mudas: massa da matéria fresca das mudas (média de $579 \mathrm{mg}$ por plântula), número de folhas por muda (média de 5,1), massa da matéria seca (média de $74 \mathrm{mg}$ por plântula) e altura da parte aérea (média de 4,9 cm). Estes resul- tados comprovam o maior efeito do nitrogênio, em comparação ao potássio, nas características vegetativas das mudas, conforme relatado por Higuti et al. (2010) em abobrinha. Dufault (1985) e Melton \& Dufault (1991) também não obtiveram diferenças significativas nas características de mudas variando doses de potássio em salsão e tomate, respectivamente.

Puga et al. (2010), estudando o efeito da omissão de macronutrientes no crescimento da chicória, relataram que a omissão do nitrogênio e do potássio afeta o crescimento das plantas, reduzindo a altura, o número de folhas, a área foliar e a massa seca da parte aérea, quando comparado ao tratamento completo. No entanto, no presente trabalho, mesmo a ausência de potássio não afetou estas características, provavelmente pela baixa necessidade nesta fase inicial e porque a fibra apresenta cerca de $1,22 \%$ de $\mathrm{K}_{2} \mathrm{O}$ que pode ter sido liberado e absorvido 
pelas raízes. O potássio não participa de combinações orgânicas, sendo um elemento ativo, porém livre, o que faz com que seja prontamente liberado quando se utilizam adubos orgânicos (Ernani et al., 2007; Kiehl, 2010; Magro et al., 2010). Provavelmente o mesmo deve ocorrer com a fibra de coco, que é um material orgânico, mesmo que em pequena quantidade, conforme relatado por Oliveira et al. (2009).

As doses de potássio em fertirrigação também não afetaram as características das plantas na colheita, não se obtendo diferença para a massa da matéria fresca (média de $385 \mathrm{~g}$ por planta), altura (média de $19 \mathrm{~cm}$ ), número de folhas (média de 60 por planta) e diâmetro das "cabeças" (média de 37 $\mathrm{cm})$. Os valores obtidos nesta pesquisa com doses de potássio foram próximos do melhor tratamento com doses de nitrogênio, o que pode ser explicado pela dose utilizada deste nutriente $(80$ $\mathrm{mg}$ de $\mathrm{N} \mathrm{L}^{-1}$ ) ter sido muito próxima da dose ótima estimada ( 88 a $91 \mathrm{mg}$ de $\mathrm{N}$ $\mathrm{L}^{-1}$ ) na pesquisa com nitrogênio.

Os resultados obtidos nestes experimentos, principalmente o de nitrogênio, ratificam a importância do estudo do desenvolvimento das mudas até o final do ciclo. Se este trabalho fosse interrompido na data do transplante, apenas com avaliação das mudas, poder-se-ia concluir, erroneamente, que quanto maior a dose de nitrogênio, melhores (maior massa, altura e número de folhas) as mudas. Porém, mudas com maior massa e altura não resultam, necessariamente, em maior produção, corroborando com Minami (2010) que afirma que uma muda de qualidade não precisa ser muito comprida ou a maior. Quando as condições ambientais após o transplante forem próximas das ideais para o desenvolvimento das plantas, pequenas diferenças nas características vegetativas observadas nas mudas podem não se manter até a produção final, conforme observado por Kano et al. (2008), em couve-brócolo, e por Magro et al. (2011), em repolho.

Conclui-se que a adubação química com potássio via fertirrigação, na produção de mudas de chicória em bandejas com fibra de coco como substrato, não afeta as características das mudas e a produção final da cultura, enquanto que para o nitrogênio a melhor dose estimada é de cerca de $90 \mathrm{mg}$ de $\mathrm{N} \mathrm{L}^{-1}$, aplicada semanalmente na fase de produção de mudas da chicória.

\section{REFERÊNCIAS}

BRAGA DO; SOUZA RB; CARRIJO AO; LIMA JL. 2007. Produção de mudas de pimentão em diferentes substratos a base de fibra de coco verde sob fertirrigação. In CONGRESSO BRASILEIRO DE OLERICULTURA, 47. Resumos... Porto Seguro: ABH (CD-ROM).

CARRIJO OA; LIZ RS; MAKISHIMA N. 2002. Fibra da casca do coco verde como substrato agrícola. Horticultura Brasileira 20: 533-536.

COSTA CA; RAMOS SJ; SAMPAIO RA; GUILHERME DO; FERNANDES LA. 2007. Fibra de coco e resíduo de algodão para substrato de mudas de tomateiro. Horticultura Brasileira 25: 387-391

CUNHA AR; MARTINS D. 2009. Classificação climática para os municípios de Botucatu e São Manuel, SP. Irriga 14: 1-11.

DUFAULT R. 1985. Relationship among nitrogen, phosphorus, and potassium on celery transplant growth. HortScience 20: 1104-1106.

ERNANI PR; ALMEIDA JA; SANTOS FC. 2007. Potássio. In: NOVAIS, RF. et al. (org). Fertilidade do Solo. 1 ed. Viçosa: Sociedade Brasileira de Ciência do Solo, v. 1, p. 551-594.

FELTRIM AL; CECÍLIO FILHO AB; REZENDE BLA; BARBOSA JC. 2006. Produção de chicória em função do período de cobertura com tecido de polipropileno. Horticultura Brasileira 24: 249-254.

FILGUEIRA FAR. 2008. Novo manual de olericultura: agrotecnologia moderna na produção e comercialização de hortaliças. Viçosa: UFV. 421p.

HIGUTI ARO; SALATA AC; GODOY AR; CARDOSO AII. 2010. Produção de mudas de abóbora com diferentes doses de $\mathrm{N}$ e $\mathrm{K}$. Bragantia 69: 377-380.

KANO C; GODOY AR; HIGUTIARO; CASTRO MM; CARDOSO AII. 2008. Produção de couve-brócolo em função do tipo de bandeja e idade das mudas. Ciência e Agrotecnologia 32: $110-114$.

KIEHL EJ. 2010. Novo fertilizantes orgânicos. Piracicaba: $1^{\text {a }}$ edição do autor. $248 \mathrm{p}$.

MAGRO FO; ARRUDA N; CASA J; SALATA AC; CARDOSO AII; FERNANDES DM. 2010. Composto orgânico na produção e qualidade de sementes de brócolis. Ciência e Agrotecnologia 34: 596-602.

MAGRO FO; SALATA AC; BERTOLINI EV; CARDOSO AII. 2011. Produção de repolho em função da idade das mudas. Revista AgroAmbiente On-line 5: 119-123.

MELTON RR; DUFAULT RJ. 1991. Tomato seedling growth, earliness, yield, and quality following pretransplant nutritional conditioning and low temperatures. Journal of American Society for Horticultural Science 116: 421-425.

MINAMI K. 2010. Produção de mudas de alta qualidade. Piracicaba: Degaspari. 440p.

MÜLLER SF; MEINERZ CC; CASTAGNARA DD. 2010. Efeito de urina-de-vaca na fertilização de mudas de chicória. Cadernos de Agroecologia 5: 1-4.

OLIVEIRA AB; HERNANDEZ FFF; ASSIS JÚNIOR RN. 2009. Absorção de nutrientes em mudas de berinjela cultivadas em pó de coco verde. Caatinga 22: 139-143.

PUGA AP; PRADO RM; CORREIA MAR; ALMEIDA TB. 2010. Omissão de macronutrientes no crescimento e no estado nutricional da chicória cultivada em solução nutritiva. Revista Agrarian 3: 56-62.

RAIJ BVan.; ANDRADE JC; CANTARELLA H; QUAGGIO JA. 2001. Análise química para avaliação da fertilidade de solos tropicais. Campinas: Instituto Agronômico de Campinas. 285p.

RAMOS ARP; DIAS RCS; ARAGÃO CA; MENDES MAS. 2012. Mudas de melancia produzidas com substrato à base de pó de coco e soluções nutritivas. Horticultura Brasileira 30: 339-344.

REGHIN MY; OTTO RF; OLINK JR; JACOBY CFS. 2007. Produtividade da chicória (Cichorium endivia L.) em função de tipos de bandejas e idade de transplante de mudas. Ciência e Agrotecnologia 31: 739-747.

SÁ GD; REGHIN MY. 2008. Desempenho de duas cultivares de chicória em três ambientes de cultivo. Ciência e Agrotecnologia 32: 378-384.

SAMPAIO RA; RAMOS SJ; GUILHERME DO; COSTA CA; FERNANDES LA. 2008. Produção de mudas de tomateiro em substratos contendo fibra de coco e pó de rocha. Horticultura Brasileira 26: 499-503.

SILVEIRA EB; RODRIGUES VJLB; GOMES AMA; MARIANO RLR; MESQUITA JCP. 2002. Pó de coco como substrato para produção de mudas de tomateiro. Horticultura Brasileira 20: 211-216.

SOUNDY P. 1996. Lettuce transplant root and shoot growth and development in relation to nitrogen, phosphorus, potassium, and water management. $318 \mathrm{p}$. (Tese doutorado).

TRANI PE; PASSOS FA; AZEVEDO FILHO JA. 1997. Alface, almeirão, chicória, escarola, rúcula e agrião d'água. In: RAIJ BVan; CANTARELLA H; QUAGGIO JA; FURLANI AMC. Recomendações de adubação e calagem para o estado de São Paulo. 2. ed. Campinas: Instituto Agronômico e Fundação IAC. p.168-169.

TREMBLAY N; SENÉCAL M. 1988. Nitrogen and potassium in nutrient solution influence seedling growth of four vegetables species. HortScience 23: 1018-1020.

VITAL WM; TEIXEIRA NT; GALI MA; LIMA JGM; FERRARO AE; SHIGIHARA R; MIGUEL RS. 2002. Adubação na produção de mudas de alface. Revista Ecossistema 27: 63-66. 